\title{
BIOACTIVE COMPOUNDS AND ANTIOXIDANT EVALUATION OF METHANOLIC EXTRACT OF HIBISCUS SABDARIFFA
}

\author{
Stephen Adusei*
}

Department of Laboratory Technology,

University of Cape Coast, Cape Coast, Ghana

\section{Correspondence}

*Stephen Aduesi, Department of Laboratory Technology, University of Cape Coast, Cape Coast, Ghana. Email:

stephen.adusei@stu.ucc.edu.gh

\section{Present Address}

AB 11, Abiam Street, Bibiani, Western-North Region, Ghana, PO BOX 7, Bibiani, Ghana

\begin{abstract}
Hibiscus Sabdariffa (Roselle) is renowned for its delicacy and healing properties. The study aimed at evaluating the bioactive compounds (phytochemicals) and antioxidant activity of leaf, stem, and calyx of roselle, extracted with methanol. Phytochemicals were identified using numerous test methods and quantified with a UV-Vis spectrophotometer. The screening test revealed a higher number of phytochemicals in the calyx extract than the leaf or stem. With the quantification, the highest concentration was recorded in the calyx, followed by the leaf and then the stem. The antioxidant activity of the investigated plant was in the order of calyx $>$ leaf $>$ stem. Higher recoveries, ranging between $90 \%-110 \%$, was obtained for all compounds. Therefore, this study provides evidence that the leaf, stem, and calyces of roselle plants are the probable source of antioxidants and many bioactive compounds, justifying their ethnopharmacological use in conventional medicines.
\end{abstract}

\section{KEYWORDS:}

Antioxidant Evaluation, Bioactive Compounds, Hibiscus Sabdariffa, UV-Vis Spectrophotometer

\section{1 | INTRODUCTION}

The Hibiscus Sabdariffa plant, usually known as Roselle, which is innate to India and Malaysia, is presently found in several tropical and sub-tropical countries of Africa, Asia, and the Americas ${ }^{11}$. Hibiscus Sabdariffa belongs to the family Malvaceae, which normally survives in comparatively poor soils ${ }^{[2}$. The plant is a yearly, erect, herbaceous sub-shrub with a deep root system. It is nurtured for its leaves, stem, seed, and calyces ${ }^{[2]}$.

The calyces of H. Sabdariffa have been the focus of many investigations and are identified to contain polyphenolic acids, flavonoids, and anthocyanins delphinidin-3-O-glucoside, delphinidin-3-O-sambubioside, and cyanidin-3-O-sambubioside ${ }^{3}$. In Ghana, the hot water extract of roselle calyces is used in the production of a local non-alcoholic beverage (well known in the 


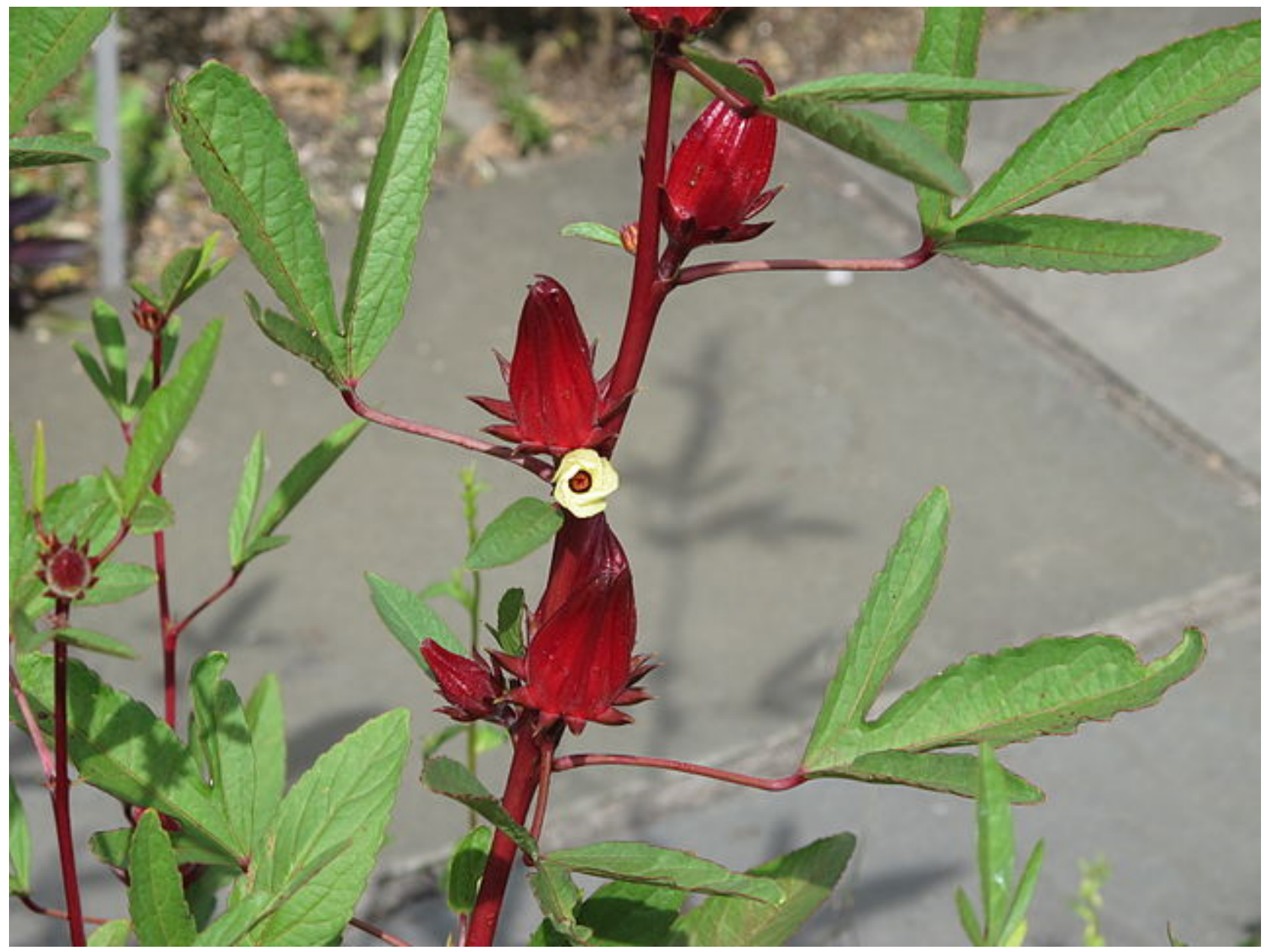

FIGURE 1 Hibiscus Sabdariffa plant displaying leaf, stem, and gloomy red calyces.

local dialect as "sobolo") and as food colorings, which is a good source of natural carbohydrate, protein and vitamin C ${ }^{44}$. In traditional medicine systems, an infusion from the calyces is used as a diuretic and to treat gastrointestinal disorders, liver diseases, fever, hypercholesterolemia, and hypertension [5]. The extract from the roselle plant has also been recounted to possess therapeutic value. It includes an antihypertensive, antiseptic, and astringent diuretic. The extract also has purgative activities remedy for cancer, abscesses, cough, dysuria, laxative, scurvy, and fever ${ }^{6}$. Phytochemicals are bioactive elements establish in plants. They include tannins, alkaloids, saponins, flavonoids, steroids, and others ${ }^{[7]}$. These bioactive elements of plants have lately become more popular and of great interest to researchers, owing to their countless medicinal uses. They have complementary and overlapping mechanisms of action in the body, including antioxidant effects, modulation of detoxification, and enzymes stimulation of the immune system, modulation of hormone metabolism, anti-bacteria, and antiviral effects ${ }^{8}$. The quantity of bioactive components in plants is influenced by agricultural management in which they are grown (fertilization, cultivation practices, etc.). The efficacy of these phytochemicals depends on their concentration in the plants ${ }^{[9}$.

Antioxidants are considered to be active inhibitors of carcinogenesis and other circumstances that are pathogenically linked with oxidative mechanisms. Reports have revealed that a lot of plants are a rich source of antioxidants. For instance, phenolic compounds such as flavonoids, tannins, and lignins in plants function as antioxidants ${ }^{[10}$. Several antioxidants perform a significant role in lessening inflammation, delaying aging, and averting cancers 11 . Studies have revealed the bioactive compounds and antioxidant activity of Hibiscus sabdariffa, frequently in the calyces and occasionally in the plant's leaf. However, little or no data on the stem has been reported, which parades the plant's worthiness in all scopes. This study aims to identify and quantify bioactive compounds (phytochemicals) and evaluate the antioxidant activity in methanolic leaf, stem, and calyx extracts of $\mathrm{H}$. Sabdariffa. A plate of H. sabdariffa (roselle) plant is shown in Figure 1. 


\section{2 | MATERIAL AND METHOD}

\subsection{Collection and Identification of Plant Material}

The plant materials (Hibiscus Sabdariffa) were collected on March 15th, 2018, from the Science market, University of Cape Coast, Cape Coast, Ghana. It was then identified and authenticated by a plant taxonomist at the herbarium of the Department of Agriculture, University of Cape Coast.

\section{2 | Preparation of Plant Material}

The fleshly collected leaf, stem, and calyx of Hibiscus Sabdariffa were cautiously cleaned and air-dried in a ventilated room for five weeks. The dried leaf, stem, and calyces were pounded into a coarse powder with a mortar and a pestle. The powdered plant materials were reserved in sealed containers for extraction.

\section{3 | Extraction of Plant Material}

The plant materials were extracted using the cold maceration method of extraction, as described by Ncube et al. 12. Thirty grams ( $30 \mathrm{~g}$ ) each of the coarsely powdered leaf, stem, and calyx of H. Sabdariffa was kept in contact with $250 \mathrm{~mL}$ of methanol in stoppered containers and allowed to stand at room temperature for three days with frequent agitation. The mixtures were then filtered through Whatman No.1 filter paper $(125 \mathrm{~mm})$ to get filtrate as extracts. The extracts were concentrated at $65{ }^{\circ} \mathrm{C}$ to onequarter of the original volume using a rotary evaporator (Stuart RE 400, United Kingdom). The dried extracts were then stored in desiccators and labeled until usage.

\section{4 | Phytochemical Examinations}

We conducted three sequential examination processes. The three processes are prelimnary phtyochemical screening test, quantitative phytochemical analysis, and antioxidant activitity determination. For the preliminary phytochemical screening tests, the standard qualitative methods by Trease and Evans ${ }^{[13]}$, Cannel ${ }^{[14]}$ and Adegoke ${ }^{[15]}$ were employed to screen for the presence of phenols, flavonoids, alkaloids, anthocyanins, anthraquinones, cardiac glycosides, terpenoids, tannins, steroids and saponins in the methanolic leaf, stem and calyx extracts of Hibiscus sabdariffa. The phytochemical screening tests were expressed as positive (+) for presence and negative (-) for the absence of a particular phytochemical. There are ten different tests.

The first test is the test for Phenols (Ferric Chloride Test). Two milliliters $(2 \mathrm{~mL})$ of 5\% aqueous ferric chloride was added to $0.2 \mathrm{~g}$ of the extracts. The formation of bluish color indicated the presence of phenols in the extracts 15 . The second test is for Flavonoids (Alkaline Reagent Test). Six drops of $2 \% \mathrm{NaOH}$ solution was added to $0.2 \mathrm{~g}$ of each extract. The formation of intense yellow color, which developed into a colorless solution upon the addition of dilute acid, indicated the presence of flavonoids in the extract ${ }^{[15]}$. The third test is for Alkaloids (Mayer's Test). Precisely $0.5 \mathrm{~g}$ of each extract was dissolved in $5 \mathrm{~mL}$ of $1 \%$ dilute $\mathrm{HCl}$ and filtered. The filtrate was treated with Mayer's reagent (Potassium mercuric iodide). The formation of a yellowcolored precipitate gave a positive result for alkaloids in the extract ${ }^{[13}$ [15]. The fourth test is for Anthocyanins (Ammonia- $\mathrm{HCl}$ Test). To the $2 \mathrm{ml}$ of the extract, $2 \mathrm{~mL}$ of $2 \mathrm{~N} \mathrm{HCl}$ were added. The appearance of a pink-red color that turned purplish-blue after the addition of ammonia indicated anthocyanins $\underline{13}$. The fift test is for Anthraquinones (Borntrager's Test). To the $10 \mathrm{~mL}$ of benzene, a small quantity of the extract was added and shaken. The content was filtered, and $5 \mathrm{~mL}$ of $10 \%$ ammonia solution was added to the filtrate, and the mixture then was shaken. No change in color in the ammoniacal layer (lower phase) indicates free anthraquinones $[14$.

The sixth test is for Cardiac Glycosides (Kella-Killani Test). The five milliliters ( $5 \mathrm{~mL}$ ) of glacial acetic acid containing a trace of ferric chloride was added to $0.5 \mathrm{~g}$ of the extract in a $20 \mathrm{~mL}$ test tube. The test tube was held at $45^{\circ} \mathrm{C}$, and $1 \mathrm{~mL}$ of concentrated $\mathrm{H} 2 \mathrm{SO} 4$ was carefully added down the side. A purple ring color at the interface indicated the presence of cardiac glycoside ${ }^{14 .}$. The seventh test is for Terpenoids (Salkowski's Test). The half a milliliter $(0.5 \mathrm{~mL})$ of chloroform was added to $0.1 \mathrm{~g}$ of extract, followed by $1 \mathrm{~mL}$ of concentrated sulphuric acid. The formation of reddish-brown precipitate gave the presence of terpenoids in the extract ${ }^{[13]}$. The eight test is for Tannins (Ferric Chloride Test). To the $0.2 \mathrm{~g}$ of the extract, an equal volume of distilled water was added in a test tube, followed by three drops of dilute ferric chloride. The formation of brownish blue or dark color indicated tannins in the extract ${ }^{[15]}$. The nineth test is for Steroids (Liebermann-Burchard's Test). The half a gram $(0.5 \mathrm{~g})$ of each extract was mixed with $2 \mathrm{~mL}$ of chloroform. Two milliliters $(2 \mathrm{~mL})$ of concentrated sulphuric acid was then added to the mixture in a 
test tube. The formation of red color in the lower chloroform layer showed steroids' presence in the extract ${ }^{[15]}$. The last test is for Saponins (Foam Test). The six milliliters $(6 \mathrm{~mL})$ of distilled water was added to $0.2 \mathrm{~g}$ of the extract and shaken vigorously in a graduated cylinder for 15 minutes. The development of bubbles or persistent foam for 10 minutes indicated the presence of saponins in the extract 14 .

\section{5 | Quantitative Phytochemical Analysis}

The quantitative assay of the methanolic leaf, stem, and calyx extracts of Hibiscus sabdariffa was performed for total phenols, flavonoids, saponins, and alkaloids. There are four quantitative phytochemical analyses, i.e. the determination of total phenol content by Folin-Ciocalteu Assay, the determination of total flavonoid content by Aluminum Chloride Colorimetric Method, the determination of total saponin content by Vanillin-sulphuric Acid Colorimetric Assay, and the determination of total alkaloid content.

The determination of the total phenol content was carried out according to the method by Ainsworth and Gillespie ${ }^{[16}$. Twentyfive microliters $(25 \mu \mathrm{L})$ of gallic acid standard solutions $(5,10,20,30,40$, and $50 \mu \mathrm{g} / \mathrm{mL})$ or H. sabdariffa extracts were mixed with $40 \mu \mathrm{L}$ of Folin-Ciocalteu reagent. After 5 minutes, $200 \mu \mathrm{L}$ of sodium carbonate solution $(7.5 \%$, w/v) was added and allowed to stand at $20^{\circ} \mathrm{C}$ in a water bath for 90 minutes. The reaction mixture was measured at $765 \mathrm{~nm}$ on a UV-VIS spectrophotometer (Shimadzu UV mini-1240, Ontario, Canada). The results were expressed as mg gallic acid equivalent/g of dry weight (mg GAE/g DW), based on the calibration curve.

The aluminum chloride colorimetric method, as described by Piyanete et al. ${ }^{[17}$, was used to determine the total flavonoid content of H. sabdariffa extracts. Using Quercetin as standard, the flavonoid content was determined as a quercetin equivalent. The following concentrations $(10,25,50,75$, and $100 \mu \mathrm{g} / \mathrm{mL})$ were prepared in methanol from the standard quercetin solution. A hundred microliters $(100 \mu \mathrm{L})$ of each of the quercetin dilution was mixed with $500 \mu \mathrm{L}$ of distilled water and then with $100 \mu \mathrm{L}$ of $5 \%$ sodium nitrate and allowed to stand for 6 minutes. Then $150 \mu \mathrm{L}$ of $10 \%$ aluminum chloride solution was added and allowed to stand for 5 minutes after which $200 \mu \mathrm{L}$ solution of $1 \mathrm{M}$ sodium hydroxide was added sequentially. The reaction mixture was measured at $510 \mathrm{~nm}$ with a UV-VIS spectrophotometer (Shimadzu UV mini-1240, Ontario, Canada). It resulted expressed as $\mathrm{mg} / \mathrm{g}$ quercetin equivalent (QE) of dry extract, based on the calibration curve.

The determination of the total saponin content was carried out according to the method as described by Moja et al. ${ }^{[18]}$ with slight modifications from Adusei et al. ${ }^{119}$. A method based on vanillin-sulphuric acid colorimetric reaction. Exactly $5000 \mu \mathrm{L}$ of water was added to $100 \mu \mathrm{L}$ of Diosgenin. Five hundred microliters $(500 \mu \mathrm{L})$ of vanillin reagent $(8 \mathrm{~g}$ of vanillin in $100 \mathrm{~mL}$ of $99.5 \%$ ethanol) was added. Five milliliters $(5 \mathrm{~mL})$ of $72 \%$ sulphuric acid were also added and mixed well. This solution was kept in a water bath at $60{ }^{\circ} \mathrm{C}$ for 10 minutes. After 10 minutes, it was cooled, and the absorbance read at $544 \mathrm{~nm}$ and recorded. All measurements were performed in triplicate for each analysis. The total saponin content determined from the linear equation of a standard curve prepared with Diosgenin and expressed as $\mathrm{mg} / \mathrm{g}$ diosgenin equivalent (DE) of dry extract.

The total alkaloid content of H. sabdariffa extracts was determined according to a slightly modified method of Adusei et al. 19. One gram of crude extract of each leaf, stem, and calyx was weighed into a $100 \mathrm{~mL}$ beaker, and $50 \mathrm{~mL}$ of $10 \%$ hydrochloric acid in ethanol was added and covered and allowed to stand for 4 hours. The extract was filtered, and the filtrate was concentrated at $65{ }^{\circ} \mathrm{C}$ to one-quarter of the original volume using a rotary evaporator (Stuart RE 400, United Kingdom). Fifteen (15) drops of concentrated ammonium hydroxide were then added dropwise to the concentrate until the precipitation was complete. After 3 hours of mixture sedimentation, the supernatant was discarded, and the precipitates were washed with $20 \mathrm{~mL}$ of $0.1 \mathrm{M}$ ammonium hydroxide and then filtered. The residue was the alkaloid, which was dried and weighed. The percentage alkaloid was then calculated as the weight of residue $\mathrm{x} 100$ / weight of sample taken and results expressed as \%w/w of dry extracts.

\section{6 | Antioxidant Activity Determination}

The assay for antioxidant activity of H. sabdariffa was based on the reduction of Molybdate (VI) to Molybdate (V) by the extract and subsequent formation of green phosphate/MO (V) complex at acid pH as described by Akinmoladun et al. 20, with slight modifications from Adusei et al. (2019). Ascorbic acid was used as a standard. One milliliter (1 mL) of $0.6 \mathrm{M}$ sulphuric acid, $28 \mathrm{mM}$ of sodium phosphate, and four $\mathrm{mM}$ of ammonium molybdate were added in $20 \mathrm{~mL}$ of distilled water and made up to the volume of $50 \mathrm{~mL}$ by adding distilled. One-third of a gram $(0.3 \mathrm{~g})$ of the extract was measured into three separate test tubes. One-third of a milliliter $(0.3 \mathrm{~mL})$ of the molybdate reagent solution was then added. These tubes were kept incubated at 95 OC 
TABLE 1 Recoveries of analytes in methanolic extracts of Hibiscus Sabdariffa.

\begin{tabular}{lc}
\hline Analyte & Recovery \\
\hline Phenols & 110 \\
Flavonoids & 104 \\
Alkaloids & 90 \\
Saponins & 94 \\
Antioxidant & 99 \\
\hline
\end{tabular}

for 90 minutes. After incubation, the tubes were normalized to room temperature for 30 minutes. The absorbance of the reaction mixture was measured at $695 \mathrm{~nm}$ against a blank containing $100 \mu \mathrm{L}$ of methanol mixed with $900 \mu \mathrm{L}$ of reagent solution. The antioxidant activity was expressed as $\mathrm{mg} / \mathrm{g}$ ascorbic acid equivalent (AAE) of the dry extracts.

\section{7 | Statistical Analysis}

The data obtained after the experiment were analyzed using GraphPad Prism version 5.01. The results were expressed as mean \pm standard deviation. A one-way ANOVA using Tukey: compared all pairs of columns, at a 95\% confidence level was used to compare mean values among extracts. $\mathrm{P}$-values less than $0.05(\mathrm{P}<0.05)$ were considered statistically significant.

\section{3 | RESULTS AND DISCUSSION}

\section{1 | Optimization of the Cold Maceration Extraction Technique}

For the recovery of bioactive compounds (secondary metabolites) from plant sources, extraction becomes the critical stage in the technique. The extract yield is dependent on certain factors such as the nature of the solvent used with varying polarity, extraction method, nature of phytochemicals, the existence of interfering substances, and solvent to sample volume ratio ${ }^{21}$. The spike recovery experiment was a dependable technique to determine the correctness of the procedures used and the recovery of analytes (compounds of interest) from the plant material. With the spike recovery test, samples were divided into two portions, and a known quantity of a standard solution of analyte added to one portion. The analyte's concentration was determined for both the spiked, F, and unspiked portions, I, and the percent recovery, \% R, was calculated as; $\% \mathrm{R}=\mathrm{F}-\mathrm{I} / \mathrm{A} * 100$. Where "A" is the concentration of analyte added to the spiked portion ${ }^{10}$. The use of methanol as an extraction solvent presented a significantly high recovery ranging between $90 \%$ and $110 \%$, as shown in table 1 .

\section{2 | Preliminary Qualitative Phytochemical Screening}

The result of phytochemical screening on the methanolic leaf, stem, and calyx extracts of H. sabdariffa is displayed in Table 2. The calyx extract revealed the highest number (nine) of bioactive compounds (phenols, flavonoids, alkaloids, anthocyanins, anthraquinones, terpenoids, tannins, steroids, and saponins), except for cardiac glycosides being absent. The leaf extract also showed the presence of seven bioactive compounds (phenols, flavonoids, alkaloids, anthocyanins, tannins, steroids, and saponins), and the absence of three (anthraquinones, cardiac glycosides, and terpenoids). The stem extract revealed six compounds (phenols, flavonoids, alkaloids, anthocyanins, steroids, and saponins), and four (anthraquinones, cardiac glycosides, terpenoids, and tannins) being absent. This observation (many bioactive compounds revealed in the calyx extract than the leaf or stem) indicates the abundancy or richness of these compounds in the calyx than the leaf or stem. The presence and content of these bioactive compounds and other phytochemicals present in medicinal plants are mainly predisposed by the type of cultivation, genetic factors, environmental conditions, and the degree of maturation and the diversity of the plant ${ }^{21}[22$. Therefore, the result of this phytochemical test points out that Hibiscus sabdariffa possesses numerous biologically active compounds, which could serve as a possible source of drugs in herbal medicine.

\section{3 | Quantitative Determinations}

The quantitative examination was carried out for total phenols, flavonoids, saponins, alkaloids, and antioxidant activity in the methanolic leaf, stem, and calyx extracts using UV-Vis spectrophotometer with standard procedures. 
TABLE 2 Preliminary phytochemical analysis of methanolic extracts of Hibiscus Sabdariffa.

\begin{tabular}{lcccc}
\hline Bioactive compound & Test Used & Leaf & Stem & Calyx \\
\hline Phenols & FeCl3 test & + & + & + \\
Flavonoids & Alkaline reagent test & + & + & + \\
Alkaloids & Mayer's test & + & + & + \\
Anthraquinones & Borntrager's test & - & - & + \\
Cardiac Glycosides & Kella-Killani test & - & - & - \\
Anthocyanins & Ammonia-HCl test & + & + & + \\
Terpenoids & Salkowski's test & - & - & + \\
Tannins & FeCl3 test & + & - & + \\
Steroids & Liebermann-Burchard's test & + & + & + \\
Saponins & Foam test & + & + & + \\
\hline Key: $(+)$ indicates present, and (-) signifies the absence of a specific bioactive compound
\end{tabular}

TABLE 3 Quantitative data on bioactive compounds and antioxidant activity of methanolic extract of Hibiscus Sabdariffa.

\begin{tabular}{lcccc}
\hline Compounds & Leaf & $\begin{array}{c}\text { Extract } \\
\text { Stem }\end{array}$ & Calyx & P-Value \\
\hline Phenols (mg GAE/g) & $10.42 \pm 0.04 \mathrm{a}$ & $7.53 \pm 0.01 \mathrm{~b}$ & $12.25 \pm 0.03 \mathrm{c}$ & 0.0215 \\
Flavonoids (mg QE/g) & $7.58 \pm 0.01 \mathrm{a}$ & $5.41 \pm 0.03 \mathrm{~b}$ & $10.01 \pm 0.02 \mathrm{c}$ & 0.0324 \\
Saponins (mg DE/g) & $4.17 \pm 0.02 \mathrm{a}$ & $2.02 \pm 0.02 \mathrm{~b}$ & $6.67 \pm 0.01 \mathrm{c}$ & 0.0432 \\
Alkaloids (AA (mg AAE/g) & $6.41 \pm 0.03 \mathrm{a}$ & $3.34 \pm 0.01 \mathrm{~b}$ & $8.22 \pm 0.04 \mathrm{c}$ & 0.0251 \\
\hline
\end{tabular}

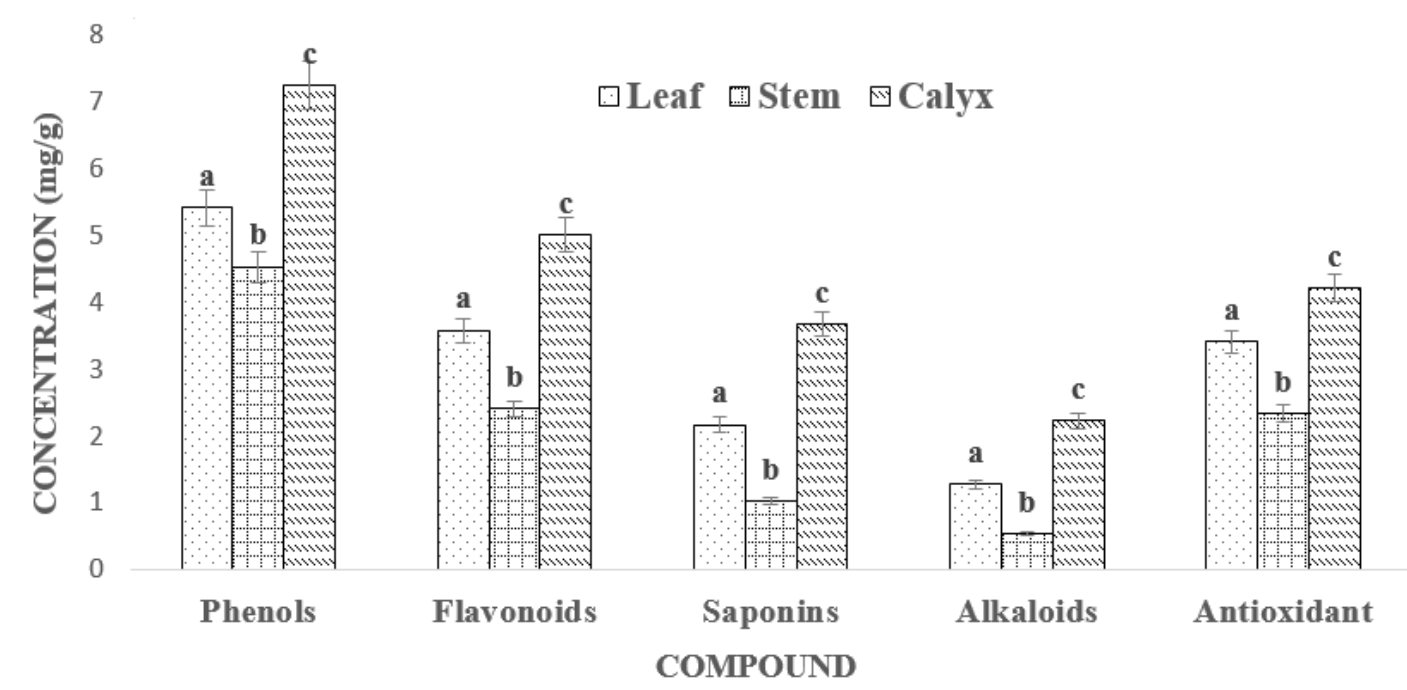

FIGURE 2 A bar chart represents bioactive compounds and antioxidant content of leaf, stem, and calyx extract of Hibiscus Sabdariffa.

The concentration of phenols, flavonoids, saponins, and alkaloids in methanolic leaf, stem, and calyx extracts of Hibiscus sabdariffa is shown in Table 3 and Figure 2. The abbreviations in column one of Table 3 can be describe as follows: GAE (Gallic Acid Equivalent), QE (Quercetin Equivalent), DE (Diosgenin Equivalent), w (Weight), AA (Antioxidant Activity), and AAE (Ascorbic Acid Equivalent). Each value is displayed as mean \pm standard deviation (SD). Means in a row with different letter superscripts are significantly different $(\mathrm{P}<0.05$, Tukey's test).Figure 2 represents bioactive compounds and antioxidant content. The results were presented as mean \pm SD of three independent experiments $(n=3)$. The different letters indicate a significant difference $(P$ $<0.05$ ). Significantly higher amounts of total phenols, flavonoids, saponins, and alkaloids were found in the calyx extract than the leaf or stem. This result implies that the above-mentioned bioactive compounds had been chiefly enriched in the calyx than the other tested parts of the plant. Although, many studies have reported the phytochemical constituents of $\mathrm{H}$. sabdariffa, mostly in the leaves and calyces of the plant. However, this current study has disclosed the concentrations of the major phytochemicals (phenols, flavonoids, saponins, and alkaloids), not only in the calyx and leaf but also in the stem, with fewer data in the literature. For each gram of the extract, phenols appear to be the most abundant bioactive compound having the maximum concentration, 
and with alkaloids being the least. Alkaloids have many pharmacological activities, including antihypertensive effects (many indole alkaloids), antiarrhythmic effects (quinidine), antimalarial activity (quinine), and anticancer actions (dimeric indoles, vincristine, vinblastine) ${ }^{[23]}$. Phenols, the most lavish bioactive compound in $\mathrm{H}$. sabdariffa of this present study, possess diverse biological activities, such as antiulcer, anti-inflammatory, cytotoxic, and antitumor activities ${ }^{24]}$. Flavonoids have also been reported to exert numerous biological property including antimicrobial, cytotoxicity, anti-inflammatory as well as antitumor activities but the best-described property of almost every group of flavonoids is their ability to act as powerful antioxidants, which can safeguard the human body from free radicals and reactive oxygen species $\overline{25 .}$. Many saponins are well-known to be antimicrobial, inhibit mold, defend plants from insect attack, and act as antifungal and antiviral in humans [26].

The antioxidant activity carried out on the methanolic leaf, stem, and calyx extracts of H. sabdariffa is displayed in table 3 and figure 2 . The calyx extract was discovered to exhibit much antioxidant property $(4.22 \pm 0.04 \mathrm{mg} / \mathrm{g})$ than the leaf $(3.41 \pm 0.03$ $\mathrm{mg} / \mathrm{g})$ or stem $(2.34 \pm 0.01 \mathrm{mg} / \mathrm{g})$. The antioxidant content of H. sabdariffa of this study higher than that reported by ${ }^{[27]} ;(2.22$ $\pm 0.04 \mathrm{mg} / \mathrm{g}$ leaves and $3.15 \pm 0.01 \mathrm{mg} / \mathrm{g}$ calyces) may be due to the differences in growing medium (soil), environmental conditions, degree of maturation and the variety of the plant. However, this present study relates the antioxidant content in the leaf, stem, and calyx extracts, with limited fact in literature. The antioxidant content of the extracts of the roselle plant in this study may also be owed to a subgroup of flavonoids and anthocyanins, which have been reported in the literature as the main constituents of $\mathrm{H}$. sabdariffa ${ }^{28}$. The results of the antioxidant activity of $\mathrm{H}$. sabdariffa of this present study corroborates that of the recent review by ${ }^{29]}$, who gave an insight into the chemotherapeutic potential of H. sabdariffa. Several antioxidants play an essential role in diminishing inflammation, delaying aging, and reduces the oxidative destruction in foods by inhibiting oxidation produced by reactive oxygen species (ROS) $\stackrel{[1]}{ }$.

\section{4 | CONCLUSION}

Medicinal plants are an abundant source of secondary metabolites (phytochemicals). This study has revealed that Hibiscus Sabdariffa, a medicinal and food plant, is rich in many phytochemicals such as phenols, flavonoids, anthocyanins, and alkaloids, and many others, which are accountable for its pharmacological possessions. The antioxidant content was established to be higher in the calyx than the leaf or stem of the plant. Hence, the plant's calyces should be chosen for natural antioxidant roles and therapeutic purposes in traditional medicine systems. Therefore, Hibiscus Sabdariffa is a unique source of a broad spectrum of bioactive compounds having diverse medicinal assets, which could be a probable curative agent in plant medicine.

\section{References}

1. O B, OO A. Microbiological and Physico-chemical Evaluation of some Non-alcoholic Beverages. Pakistan Journal of Nutrition 2004;3:188-192.

2. Akindahunsi A, Olaleye M. Toxicological investigation of aqueous-methanolic extract of the calyces of Hibiscus sabdariffa L. Journal of ethnopharmacology 2003;89(1):161-164.

3. BH A, Al W, G B. Phytochemical, pharmacological and toxicological aspects of Hibiscus sabdariffa L. Phytotherapy research 2008;19(5):369-375.

4. IS O, OE N, UB OU. Changes in the quality of Zobo beverages produced from Hibiscus sabdariffa (Linn Roselle) and the effects of extract of ginger alone or in combination with refrigeration. African Journal of Biotechnology 2007;7(8):11761180.

5. y Ortiz C M, P CE. Plantas Medicinales Utilizadas en el Estado de Morelos. 2 ed. CCNABIO; 2007.

6. Osueke J, Ehirim F. Chemical, nutritional and sensory analysis of zobo drink (var sabdariffa) and selected soft drinks. Journal of Agriculture and Food Sciences 2004;2(1):21-24.

7. Thakuria P, Nath Professor R, Sarma Professor S, Kalita Professor D, Dutta Professor D, Borah Professor P, et al. Phytochemical screening of medicinal plants occurring in local area of Assam. Journal of Pharmacognosy and Phytochemistry JPP 2018;186(73). 
8. SN K, S T, AO J. Studies on Bioactive Saponins from Chinese Medicinal Plants. Advances in Experimental Medicine and Biology 2006;404:371-382.

9. Koche D, Shirsat R, Kawale M. An overerview of major classes of phytochemicals: their types and role in disease prevention. Hislopia Journal 2016;9:1-11.

10. Suffredini I, Sader H, Goncalves A. Screening of antibacterial extracts from plants native to the Brazilian amazon rain forest and Atlantic forest. Braz J Med Biol Res 2004;37:379-384.

11. Altemimi A, Lakhssassi N, Baharlouei A, Watson DG, Lightfoot DA. Phytochemicals: Extraction, isolation, and identification of bioactive compounds from plant extracts. Plants 2017;6(4):42.

12. Ncube N, Afolayan A, Okoh A. Assessment techniques of antimicrobial properties of natural compounds of plant origin: current methods and future trends. African journal of biotechnology 2008;7(12):1797-1806.

13. Trease G, Evans W. Pharmacognosy. 2002. 15 ed. Harbcourt publishers Ltd., WB Saunders Company Ltd; 2002.

14. Cannel R. Methods in Biotechnology. Natural Products Isolation. Human press, New Jersey; 2000.

15. Adegoke A, Iberi P, Akinpelu D, Aiyegoro O, Mboto C. Studies on phytochemical screening and antimicrobial potentials of Phyllanthus amarus against multiple antibiotic resistant bacteria. International Journal of Applied Research in Natural Products 2010;3(3):6-12.

16. Ainsworth EA, Gillespie KM. Estimation of total phenolic content and other oxidation substrates in plant tissues using Folin- Ciocalteu reagent. Nature protocols 2007;2(4):875-877.

17. C P, P M, W N. Antioxidant activities and phenolic contents of extracts from Salvinia molesta and Eichornia Cressipes. Res J Biol Sci 2009;4:1113-1117.

18. F M, M K, N G, HR V. Phytochemical screening of some species of Iranian plants. Iranian Journal of Pharmaceutical Resource 2003;5:77-82.

19. Adusei S, Otchere JK, Oteng P, Mensah RQ, TeiMensah E. Phytochemical analysis, antioxidant and metal chelating capacity of Tetrapleura tetraptera. Heliyon 2019;5(11):e02762.

20. Akinmoladun AC, Ibukun E, Afor E, Obuotor EM, Farombi E. Phytochemical constituent and antioxidant activity of extract from the leaves of Ocimum gratissimum. Scientific Research and Essays 2007;2(5):163-166.

21. Koleva II, Van Beek TA, Linssen JP, Groot Ad, Evstatieva LN. Screening of plant extracts for antioxidant activity: a comparative study on three testing methods. Phytochemical Analysis: An International Journal of Plant Chemical and Biochemical Techniques 2002;13(1):8-17.

22. Melo EdA, Maciel MIS, Lima VLAG, Leal FLL, Caetano ACdS, Nascimento RJ. Antioxidant capacity of vegetables commonly consumed. Food Science and Technology 2006;26(3):639-644.

23. M W, T S, B LB. Modes of action of allele chemical alkaloids: interaction with neuro receptors, DNA and other molecular targets. Journal of chemical ecology 2010;24:1888-1937.

24. Silva E, Souza J, Rogez H, Rees JF, Larondelle Y. Antioxidant activities and polyphenolic contents of fifteen selected plant species from the Amazonian region. Food chemistry 2007;101(3):1012-1018.

25. Tapas AR, Sakarkar D, Kakde R. Flavonoids as nutraceuticals: a review. Tropical journal of Pharmaceutical research 2008;7(3):1089-1099.

26. Traore F, Faure R, Ollivier E, Gasquet M, Azas N, Debrauwer L, et al. Structure and antiprotozoal activity of triterpenoid saponins from Glinus oppositifolius. Planta Medica 2000;66(4):368-371.

27. Formagio A, Ramos D, Vieira M, Ramalho S, Silva M, Zárate N, et al. Phenolic compounds of Hibiscus sabdariffa and influence of organic residues on its antioxidant and antitumoral properties. Brazilian Journal of Biology 2015;75(1):69-76. 
28. Tsai PJ, McIntosh J, Pearce P, Camden B, Jordan BR. Anthocyanin and antioxidant capacity in Roselle (Hibiscus sabdariffa L.) extract. Food research international 2002;35(4):351-356.

29. Lasker YB, Mazumder PB. Insight into the molecular evidence supporting the remarkable chemotherapeutic potential of Hibiscus sabdariffa L. Biomedicine and Pharmacotherapy 2020;127:110153.

How to cite this article: Adusei S., (2020), Bioactive Compounds and Antioxidant Evaluation of Methanolic Extract of Hibiscus Sabdariffa, IPTEK The Journal of Technology and Science, 31(2):139-146. 